\title{
"Bye bye, Brasil" - \\ O declínio das religiões tradicionais no Censo 2000
}

\author{
ANTÔNIO FLÁVIO PIERUCCI
}

\section{Pós-tradicionalização religiosa acelerada}

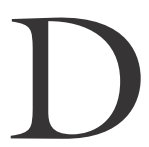

O PONTO DE VISTA da composição religiosa da população de nosso País, tudo leva a crer que estamos numa hora de decisiva inflexão. Do específico ponto de vista de uma demografia religiosa, o início do século XXI vem bater como um momento de despedida. Hora de adeus - mais uma! - em que nos afastamos um pouco mais, agora mais aceleradamente e muito mais inapelavelmente, de um certo Brasil tradicional, vale dizer, do que ainda resta de Brasil tradicional no campo das religiões em nosso território, campo esse que costumávamos supor em grande medida tributário dos comportamentos tradicionais, afeito mais que os outros ao cultivo de tradições e tradicionalismos teóricos e práticos, para não falar da centralidade da tradição tout court como transmis$s \tilde{a} o$, garantia de permanência de toda e qualquer imagem de mundo religiosa. Não à toa, a antiga reza católica do "glória ao Pai” concluía em palavras desejantes: “assim como era no princípio, agora e sempre por todos os séculos dos séculos, amém". Não é mais assim. Isso está acabando. Bye, bye!

Três das principais religiões classificadas pela sociologia como tradicionais, mesmo que cada qual seja tradicional à sua maneira, mostram hoje sérios sinais de cansaço, mais do que isso, de exaustão em sua capacidade de reprodução ampliada.

Em primeiro lugar, o catolicismo, esse que um dia se pensou triunfalmente nos haver cunhado, em cultura e civilização, católicos no todo e de uma vez por todas, selando-nos o destino confessional desde a primeira hora: católicos de berço e de colo. Do berço eucarístico, representado na mitificada "primeira missa" ${ }^{1}$ celebrada por Frei Henrique de Coimbra, em Porto Seguro, no dia 26 de abril de 1500, ao colo mariano, tornado trono em 1930, abertura da Era Vargas, com a proclamação de Nossa Senhora Aparecida como a "padroeira universal do Brasil"2.

Em segundo lugar, o luteranismo, a primeira das formações do antigo protestantismo a se enraizar em solo brasileiro, que aqui desembarcou, para aqui ficar, com as primeiras levas de colonização alemã no início do primeiro Império, instalando-se, etnicamente autocentrado e espontaneamente segregado, meio 
livre, meio emparedado, num circundante Brasil oficialmente católico. Ninguém fala muito nisso, sabe-se lá por quê, mas o luteranismo, "tipo-ideal-em-carne-eosso" do chamado "protestantismo de imigração", também se mostra numericamente minguante neste Brasil que adentra o século XXI. Seu decréscimo relativo é menor que o do catolicismo, mas é notável, até como sintoma.

$\mathrm{E}$, finalmente, a umbanda. Finalmente mas não menos importante, dada a significação cultural que adquiriu em nossa história republicana aos olhos de toda uma elite intelectual que se deixou embalar na crença de um "Brasil brasileiro" e se empenhou na enunciação normativa de uma especificidade identitária que seria brasileira porque sincrética ${ }^{3}$. Celebrada em prosa e verso, em música e letra, como "a" religião brasileira por excelência, primeira e única, misturada mas genuína, também a umbanda se apresenta, para espanto geral dos menos informados, em gradual retração numérica.

\section{O ocaso quase fim da maioria católica}

Não deixa de ser interessante verificar, pelos dados do IBGE (Tabela 1), que no início do século XXI os católicos ainda representam três quartos $(73,8 \%)$ da população brasileira, o que, em números absolutos, soa até mais alto, maior: a quantidade de brasileiros que se declaram católicos no início do novo século é enorme, superior a 125 milhões (Tabela 2). Dez anos atrás, eram 122 milhões. Só esse acréscimo de três milhões de católicos em uma década supera em muito o séquito inteiro de uma igreja pentecostal das grandes. Pelo viés dos números absolutos, o catolicismo continua amplamente majoritário e se destaca nas tabelas do IBGE contra o fundo das outras confissões, minoritárias. E continua crescendo, embora a taxas bem inferiores às do crescimento da população. Ocorre, entretanto, que em números relativos, proporcionais, o que salta aos olhos é que a confissão majoritária está cada vez menor.

O catolicismo no Brasil diminui de tamanho, mostra o Censo Demográfico de 2000. O exato seria dizer que mostra isso uma vez mais, como aliás tem feito sempre, compassando a intervalos regulares de dez anos um declínio que é constante, persistente (ver Tabela 1), e que por mal dos pecados, a despeito de todos os esforços em contrário das autoridades eclesiásticas e de uma sempre rejuvenescida militância católica, parece impor-se ao catolicismo brasileiro como um fado: inexorável.

Mas não seria justamente essa, segundo a mais clássica das sociologias, a ineludível sina das religiões tradicionais majoritárias em qualquer parte do mundo à medida que as sociedades se modernizam e ao se modernizar se diferenciam, uma fatalidade sociocultural quase tão implacável quanto a genética dos caranguejos? No declínio do catolicismo em países que tradicionalmente têm sido de maioria católica materializa-se, é bom lembrar, uma tendência mais geral, quase uma lei que se repete em todas as grandes culturas religiosas que se constituíram desde a mais remota antigüidade oriental até o final da modernidade clássica 
ocidental: a de perder terreno. É o que anda acontecendo, por exemplo, com o hinduísmo na Índia, basta prestar atenção: pois se ali se expandem os muçulmanos, tal se faz em detrimento das hostes tradicionalmente hinduístas. A cada avanço demográfico do islã dentro daquelas fronteiras, é o hinduísmo que sai perdendo, assim como o catolicismo brasileiro perde terreno a cada avanço pentecostal. Não há mágica alguma nessa história, mistério algum, nem há como escapar se o jogo censitário com tabelas é de soma zero.

Não há, pois, nesse refluxo, desdouro algum para o catolicismo brasileiro. Nas sociedades pós-tradicionais, et pour cause, decaem as filiações tradicionais. Nelas os indivíduos tendem a se desencaixar de seus antigos laços, por mais confortáveis que antes pudessem parecer. Desencadeia-se nelas um processo de desfiliação em que as pertenças sociais e culturais dos indivíduos, inclusive as religiosas, tornam-se opcionais e, mais que isso, revisáveis, e os vínculos, quase só experimentais, de baixa consistência. Sofrem fatalmente com isso, claro, as religiões tradicionais.

Desde o começo, e isso remonta aos anos de 1950, a sociologia da religião praticada no Brasil foi sempre uma sociologia do catolicismo em declínio. Aliás, não só no Brasil. Em toda a América Latina. Mesmo os estudos sociológicos voltados para religiões não-católicas, se enfocarem a expansão quantitativa de uma delas, seja qual for, estarão sempre fazendo, pelo avesso, uma sociologia do declínio do catolicismo. É inevitável. Desde que me conheço por sociólogo - e de saída fui aprender a fazer sociologia no antigo Cebrap, onde entrei em 1971 - é exatamente isso que tem sido feito e dito, sem rodeios nem exclamações, pela sociologia brasileira da religião, calçada tanto em dados censitários quanto em macroteorias sociológicas de amplo consenso entre os pares. Logo que comecei a praticar sociologia, especializando-me já então em sociologia da religião sob a batuta do grande mestre Candido Procopio, aprendi que o exame dos censos brasileiros de 1940, 1950 e 1960 - a despeito das limitações inerentes ao tipo de informação que um censo demográfico costuma apresentar, como por exemplo a impossibilidade de resposta múltipla, o que de cara exclui do registro censitário os sincretismos todos e as (mal)chamadas " "duplas filiações" - revelava "a tendência geral para um declínio moderado, mas constante, de adeptos da Igreja Católica" ${ }^{5}$. E os protestantes, liderados pelos pentecostais, mas também as religiões mediúnicas (kardecismo, umbanda e candomblé) e os que se declaravam "sem religião", vinham apontados como os principais "beneficiários desse pro-

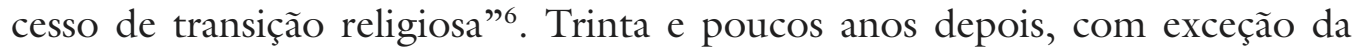
umbanda, que para surpresa geral hoje vê encolhido seu número de adeptos, as tendências registradas no início da década de 1970 pela equipe de Candido Procópio estão sendo confirmadas pelo censo 2000. More of the same, portanto: o catolicismo em declínio, os pentecostais e os sem religião em escalada. A diferença é que essas curvas agora se desenham de forma bem mais pronunciada, $\mathrm{O}$ ritmo ficou mais acelerado. 
Tabela 1 - Religiões do Brasil de 1940 a 2000, em porcentagem

\begin{tabular}{l|c|c|c|c|c|c|c}
\hline \multicolumn{1}{c|}{ Religião } & 1940 & 1950 & 1960 & 1970 & 1980 & 1991 & 2000 \\
\hline Católicos & 95,2 & 93,7 & 93,1 & 91,1 & 89,2 & 83,3 & 73,8 \\
\hline Evangélicos & 2,6 & 3,4 & 4,0 & 5,8 & 6,6 & 9,0 & 15,4 \\
\hline $\begin{array}{l}\text { Outras } \\
\text { religiões }\end{array}$ & 1,9 & 2,4 & 2,4 & 2,3 & 2,5 & 2,9 & 3,5 \\
\hline Sem religião & 0,2 & 0,5 & 0,5 & 0,8 & 1,6 & 4,8 & 7,3 \\
\hline T O T A L (*) & $100,0 \%$ & $100,0 \%$ & $100,0 \%$ & $100,0 \%$ & $100,0 \%$ & $100,0 \%$ & $100,0 \%$ \\
\hline
\end{tabular}

(*) Não inclui religião não declarada e não determinada. Fonte: IBGE, Censos demográficos.

Tabela 2 - As religiões do Brasil em 2000

\begin{tabular}{|c|c|c|}
\hline Religião & Número absoluto & $\%$ \\
\hline Católicos romanos & 124.976 .912 & 73,77 \\
\hline Evangélicos & 26.166 .930 & 15.44 \\
\hline Protestantes históricos & 7.159 .383 & 4,23 \\
\hline Pentecostais & 17.689 .862 & 10,43 \\
\hline Outros evangélicos & 1.317 .685 & 0,78 \\
\hline Espíritas & 2.337 .432 & 1,38 \\
\hline Espiritualistas & 39.840 & 0,02 \\
\hline Afro-brasileiros & 571.329 & 0,34 \\
\hline Umbanda & 432.001 & 0,26 \\
\hline Candomblé & 139.328 & 0,08 \\
\hline Judeus & 101.062 & 0,06 \\
\hline Budistas & 245.870 & 0,15 \\
\hline De outras orientais & 181.579 & 0,11 \\
\hline Muçulmanos & 18.592 & 0,01 \\
\hline Hinduístas & 2.979 & 0,00 \\
\hline Esotéricos & 67.288 & 0,04 \\
\hline De tradições indígenas & 10.723 & 0,01 \\
\hline De outras religiosidades & 1.978 .633 & 1,17 \\
\hline Sem religião & 12.330 .101 & 7,28 \\
\hline Declaração múltipla & 382.489 & 0,23 \\
\hline B R A S I L $\left(^{\star}\right)$ & 169.411 .759 & $100,0 \%$ \\
\hline
\end{tabular}

(*) Não inclui 387.411 casos de religião não declarada, que correspondem $0,23 \%$ da população residente total de 169.799 .170 . 
Mais um capítulo, por conseguinte, apenas mais agitado, dessa interminável novela que já dura quase setenta anos. Mas não ainda o capítulo decisivo, ainda não. Para frustração de todos os que esperavam lances mais emocionantes, a nova cara religiosa do País ainda não veio à luz, a grande virada protestante ainda não se consumou, embora continue objetivamente prometida pela seqüência dos dados, pela constância das tendências, pelas projeções mais conservadoras.

Olhemos para a Tabela 2 do ponto de vista que nos interessa neste exercício. O que o censo 2000 nos diz, por enquanto, é que o Brasil continua mudando gradualmente quanto aos componentes religiosos de sua cultura plural e sempre mais se destradicionalizando em termos religiosos. Mas adentra o novo século contando com 125 milhões de católicos declarados em 170 milhões de habitantes. Em números absolutos, é católico que não acaba mais. Basta atentar para o número absoluto de evangélicos, 26 milhões, para ver que a diferença a favor dos católicos ainda é muito grande: cem milhões. Destacado da linha declinante de sua evolução histórica, esse dado não deixa de surpreender, pois mesmo observadores muito atentos esperavam que fosse dar uma quantidade bem menor de católicos. Em certos grupos de estudiosos circularam especulações que davam como praticamente certo um rombo maior na maioria católica, que estaria reduzida à metade dos brasileiros. Era uma questão de aguardar a publicação do censo para se ver confirmada a grande virada. Na verdade, isso quase aconteceu para dois Estados da Federação, Rio de Janeiro e Rondônia, nos quais os católicos já estão na dezena dos 50\%. O Rio de Janeiro é hoje o menos católico dos Estados da Federação (Tabela 3).

Houve um longo, longo tempo e não muito antigamente, em que eram católicos mais de nove entre dez brasileiros, conforme nos mostra a série histórica dos censos demográficos disposta na Tabela 1. Em 1940: 95,2\%, caindo em 1950 para 93,7, em 1960 para 93,1 e em 1970 para 91,1. Descem da casa dos 90\% em 1980, aparecendo já na marca de 89,2. E daí por diante o ritmo das

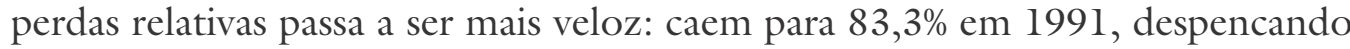
finalmente para esses 73,8 cravados em 2000.

A secular tendência do catolicismo ao minguamento demográfico não apresentando solução de continuidade, o importante a sublinhar com a Tabela 1 é a aceleração da curva declinante como um movimento demográfico que marca as duas últimas décadas do século XX, particularmente os anos de 1990. Correspondentemente, foi nos últimos vinte anos que as taxas de crescimento do conjunto dos evangélicos mais subiram. E foi sobretudo nos anos de 1990 que eles alcançaram um crescimento em tudo e por tudo extraordinário, crescendo a uma taxa praticamente de 100\% no intervalo de um decênio. Dobraram de tamanho. Em números absolutos, saltaram de treze para 26 milhões. Semelhantemente aos evangélicos, é nas duas últimas décadas do século $X X$ que o grupo dos "sem religião" passa a apresentar taxas maiores de crescimento. Categoria quase insignificante até 1980 , passam daí em diante a proliferar num ritmo de fazer inveja a 
qualquer grupo "com religião". Hoje são nada menos que 7,3\% da população. No Estado do Rio de Janeiro, os "sem religião" são hoje mais de 15\%, o que ajuda a deprimir aí a taxa de católicos para o ponto mais baixo do País: 57,2\%.

Além do Rio de Janeiro, também em Rondônia os católicos estão reduzidos a pouco mais de $57 \%$, e no Espírito Santo, Roraima e Goiás já estão na dezena dos 60\%. Em todos esses Estados, mas também no Amazonas, Acre e Tocantins, as perdas católicas da última década foram bem grandes, para não dizer fragorosas. Resulta disso que quando distribuídos pelos Estados da Federação, os números encontrados pelo censo 2000 nos dizem que, num bom número deles, o ocaso há muito anunciado, mas sempre adiado, do catolicismo como religião historicamente majoritária está se aproximando a passos largos.

Tabela 3 - Católicos, evangélicos e sem religião no Brasil em 1991 e 2000 por unidades da federação (em ordem decrescente para os católicos em 2000)

\begin{tabular}{|c|c|c|c|c|c|c|}
\hline \multirow{2}{*}{$\begin{array}{l}\text { Unidade } \\
\text { daFederação } \\
\text { Católicos } \\
\text { romanos }\end{array}$} & \multicolumn{2}{|c|}{$\begin{array}{l}\text { Católicos apostólicos } \\
\text { romanos }\end{array}$} & \multicolumn{2}{|c|}{ Evangélicos } & \multicolumn{2}{|c|}{ Sem religião } \\
\hline & 1991 & 2000 & 1991 & 2000 & 1991 & 2000 \\
\hline$\overline{\text { Piauí }}$ & 95,00 & 91,35 & 2,90 & 5,71 & 1,72 & 2,37 \\
\hline Ceará & 93,32 & 84,89 & 3,97 & 9,15 & 2,10 & 4,29 \\
\hline Paraíba & 93,03 & 84,25 & 3,65 & 9,36 & 2,81 & 5,25 \\
\hline Maranhão & 90,97 & 83,03 & 6,25 & 10,21 & 2,15 & 5,95 \\
\hline Alagoas & 91,37 & 81,93 & 3,56 & 8,61 & 4,54 & 8,13 \\
\hline Sergipe & 90,73 & 81,74 & 3,89 & 7,42 & 4,50 & 8,78 \\
\hline $\begin{array}{l}\text { Rio Grande do } \\
\text { Norte }\end{array}$ & 91,90 & 81,68 & 4,20 & 9,69 & 3,40 & 7,47 \\
\hline $\begin{array}{l}\text { Santa } \\
\text { Catarina }\end{array}$ & 86,43 & 80,27 & 11,71 & 15,48 & 0,91 & 2,26 \\
\hline Minas Gerais & 87,41 & 78,89 & 7,79 & 14,22 & 2,78 & 4,15 \\
\hline $\begin{array}{l}\text { Rio Grande do } \\
\text { Sul }\end{array}$ & 81,95 & 76,74 & 11,86 & 13,03 & 2,95 & 4,40 \\
\hline Tocantins & 89,13 & 76,02 & 8,31 & 16,01 & 1,73 & 6,06 \\
\hline Pará & 84,88 & 75,53 & 10,90 & 15,65 & 2,66 & 6,17 \\
\hline$\overline{\text { Bahia }}$ & 86,79 & 75,48 & 5,79 & 11,64 & 5,92 & 10,25 \\
\hline Amapá & 84,87 & 75,04 & 10,97 & 18,76 & 3,34 & 4,14 \\
\hline Paraná & 84,59 & 74,53 & 11,54 & 17,89 & 2,50 & 4,72 \\
\hline Pernambuco & 85,74 & 73,83 & 7,02 & 13,08 & 5,77 & 10,96 \\
\hline Mato Grosso & 83,31 & 72,91 & 11,13 & 16,15 & 3,93 & 8,00 \\
\hline$\overline{\text { São Paulo }}$ & 81,81 & 70,81 & 9,39 & 17,29 & 5,02 & 6,83 \\
\hline Amazonas & 86,37 & 70,78 & 10,01 & 19,25 & 2,39 & 6,55 \\
\hline$\overline{\text { Acre }}$ & 85,42 & 70,11 & 9,51 & 20,42 & 3,65 & 7,80 \\
\hline
\end{tabular}

Fonte: IBGE, Censos Demográficos. 


\section{O esgotamento do protestantismo de imigração}

Que o catolicismo esteja decrescendo sempre mais no Brasil não se deve apenas a uma pluralização crescente do campo religioso - deve-se também e principalmente ao crescimento vigoroso do protestantismo no maior país da "América católica". No Brasil, as igrejas evangélicas saltaram de 13.189.282 fiéis em 1991 para 26.210.545 em 2000. Tamanho duplicado.

Entretanto, se o protestantismo cresce no agregado, a coisa muda de figura quando observamos cada ramo protestante em separado. Primeiro, porque assim fica claro que o protestantismo brasileiro deve esse seu dinamismo ao superdinamismo dos ramos pentecostais e neopentecostais (cf. Mariano, 1999). E segundo, porque assim se vê que alguns ramos, em vez de crescer, regridem. É o caso dos luteranos.

Pode-se dizer que foi com a vinda dos imigrantes alemães no século XIX que o protestantismo entrou no Brasil de verdade, as a matter of fact. E entrou como luteranismo, tronco primordial da eclesialidade oriunda da Reforma. De modo mais direto, isso teve a ver com o Sul e o Sudeste do Brasil, antes de mais nada com os Estados do Rio Grande do Sul e Santa Catarina, onde se fixou entre 1824 e 1864 o contingente mais numeroso desse grupo étnico-religioso. Mas também com o Espírito Santo e Minas Gerais.

Famílias católicas havia entre os imigrantes alemães, todos sabemos, mas a grande maioria dos novos colonos era formada de adeptos de um luteranismo entranhado em seu modo de vida. O patrimônio étnico de que eram portadores confundia-se com sua pertença à eclesialidade luterana, fazendo-se ela vetor espontâneo de tradições comuns, de uma antiga língua comum, de uma mesma mentalidade, um mesmo ethos tradicional. O luteranismo trazido para o Brasil pelas sucessivas levas de alemães durante o Império era um protestantismo falado em alemão, pregado em alemão, cantado em alemão... vivido em alemão. E porque sua principal preocupação se concentrava na preservação de si como patrimônio étnico-cultural do imigrante alemão, o luteranismo brasileiro foi classificado pelos cientistas sociais como o melhor representante do chamado "protestantismo de imigração", de resto uma espécie de protestantismo tradicionalista no sentido forte do termo.

Mas vamos ao que interessa. Até meados do século XX, o luteranismo era o maior dos ramos protestantes brasileiros denominados históricos: tinha perto de quinhentos mil fiéis em 1961 e, em 1967, as contas já chegavam nos oitocentos $\mathrm{mil}^{7}$. Em 1991, quando o IBGE elaborou um ranking das dez maiores igrejas evangélicas, o luteranismo, já na marca de 1.029.679 fiéis, aparecia, contudo, em segundo lugar entre os protestantismos históricos, deslocado já do primeiro posto por conta de um expressivo crescimento dos batistas, que no censo de 1991 já passavam de 1,5 milhão de seguidores ${ }^{8}$.

A tendência das igrejas luteranas à diminuição do ritmo de crescimento só fez se acentuar no decorrer dos anos de 1990. Pelo censo de 1991, o contingente 
de luteranos perfazia 7,8\% do total geral de evangélicos. Foi o censo subseqüente, do ano 2000, que veio flagrar em números absolutos o minguado crescimento mais recente dos luteranos, indo de 1.029.679 para 1.062.144: só trinta e poucos mil a mais. Isso fez com que sua participação relativa no total do protestantismo brasileiro raleasse de quase $8 \%$ para os magros $4 \%$ atuais. Se formos fazer por tamanho uma classificação geral dos ramos evangélicos no Brasil de hoje, valendo-nos para isso do censo 2000, haveremos de constatar que, no curto intervalo de apenas uma década, a última do século XX, o luteranismo desceu da quarta para a sétima colocação.

É mais um lado do Brasil tradicional a dar mostras muito claras de uma incapacidade recém-instalada, e ao que parece invencível, de reprodução ampliada de si. É o caso de dizer mais uma vez... “bye bye, Brasil tradicional!"

\section{A retração numérica da umbanda}

Nos anos de 1960 era comum nos meios intelectuais, acadêmicos ou não, referir-se à umbanda como aquela, dentre as religiosidades afro-brasileiras, que parecia ter sido feita de encomenda não só para os negros, mas "para todos os brasileiros". The Umbanda is for All of Us é o título de um mestrado defendido na Universidade de Wisconsin pela demógrafa e socióloga paulista Maria Stella Ferreira Levy. Isso foi em 1967.

Nesse mesmo ano, precisamente em 1967, o Serviço de Estatística Demográfica, Moral e Política do Ministério da Justiça informava a quem pudesse interessar que o número de umbandistas no Brasil estava na casa dos 240 mil 240.088, para sermos exatos - e, além disso, mostrava que os brasileiros freqüentadores de centros de umbanda estavam aumentando de forma notável naquela década, quase triplicando, visto que os registros do mesmo órgão para o ano de 1964, só três anos antes, haviam chegado à existência de apenas 93.395 umbandistas. Pelos estudos de Lísias Nogueira Negrão9, especialista no tema, a década seguinte é que assistiria, particularmente no período de 1974 a 1976, “o momento culminante do crescimento da umbanda", religião que se queria "afro" porém "para todos", noutras palavras: étnica e universal.

Desde que surgiu no Rio de Janeiro na década de 1920, e já nas décadas de 1930 e 1940 começava a se disseminar pelo tecido urbano mais moderno do País, o das cidades grandes da região mais desenvolvida, o Sudeste, a umbanda foi vista como uma religião brasileira; para alguns, a religião que melhor encarnava a tradição sincrética nacional. A perspectiva da construção de uma identidade nacional esteve sempre à mão entre os intelectuais, pelo menos desde a República, o que desde logo favoreceu toda uma boa vontade com a umbanda. Afirmativamente afro e marcantemente popular, ela não se fechava etnicamente em sua negritude, mas se oferecia brasileiramente a todos os brasileiros. Pensava suas raízes como plenamente brasileiras e não simplesmente africanas. E povoava o panteão de deuses africanos, os orixás, com suas "linhas" de espíritos desencar- 
nados de personagens tipicamente brasileiros: índios, caboclos, baianos, boiadeiros etc. O africanismo brasileiro em sua forma umbandista desde sempre se apresentou e se representou como uma "mistura típica", "bem nacional", de ingredientes de proveniência diversa, porém, ressignificados como autóctones. Isso o imunizou de qualquer pudor de embarcar nas diferentes ondas de nacionalismo cultural que se manifestariam em nossa história republicana a partir dos anos de 1930.

Apesar da incensada "brasilidade" da umbanda, apesar do desejado impacto demográfico que aos olhos dos estudiosos sua recepção mereceria ter para ela assim consolidar-se no concerto (multi)cultural das religiões em nosso País, ela começou a entrar em refluxo já na década de 1980. É o que informa Lísias Negrão ${ }^{10}$. E desde então, ao que tudo indica, não parou mais de encolher aos poucos, recolhendo-se pouco a pouco, em sua fragilidade e modéstia.

A Tabela 4, que reúne dos três últimos censos demográficos as porcentagens referentes aos principais conjuntos religiosos, comparece neste artigo antes de tudo pela informação agregada que fornece a respeito das religiões afro-brasileiras. Impactados desde a Tabela 2 pelas diminutas cifras com que tanto a umbanda quanto o candomblé se mostram no censo 2000, vemos agora pela Tabela 4 que a perda de seguidores no conjunto dos cultos afro-brasileiros é lenta, gradual e contínua nas duas últimas décadas do século XX. Dos 0,57\% de brasileiros que declaravam pertencer à umbanda ou ao candomblé em 1980, apenas $0,44 \%$ o fazem em 1991 e em 2000 ainda menos: 0,34\%. A partir de 1991, quando o IBGE passou a separar umbanda de candomblé, tornou-se possível discernir qual das duas está perdendo terreno: é a umbanda, que cai de 541.518 em 1991 para 432.001 seguidores em 2000 (uma perda superior a cem mil adeptos), enquanto o candomblé, no mesmo período cresce de 106.957 para 139.329 participantes (um acréscimo superior a trinta mil adeptos) ${ }^{11}$.

Tabela 4 - Principais religiões do Brasil de 1980 a 2000

\begin{tabular}{l|c|c|c}
\hline \multicolumn{1}{c|}{ Religião } & 1980 & 1991 & 2000 \\
\hline Católicos & 89,2 & 83,3 & 73,7 \\
\hline Evangélicos & 6,6 & 9,0 & 15,4 \\
\hline Espíritas & 0,7 & 1,1 & 1,4 \\
\hline Afro-brasileiros & $0,6(0,57)$ & $0,4(0,44)$ & $0,3(0,34)$ \\
\hline Outras religiões & 1,3 & 1,4 & 1,8 \\
\hline Sem religião & 1,6 & 4,8 & 7,3 \\
\hline TOTAL $\left.{ }^{*}\right)$ & $100,0 \%$ & $100,0 \%$ & $100,0 \%$ \\
\hline
\end{tabular}

*) Não inclui religião não declarada e não determinada. Fontes: IBGE, Censos demográficos. 


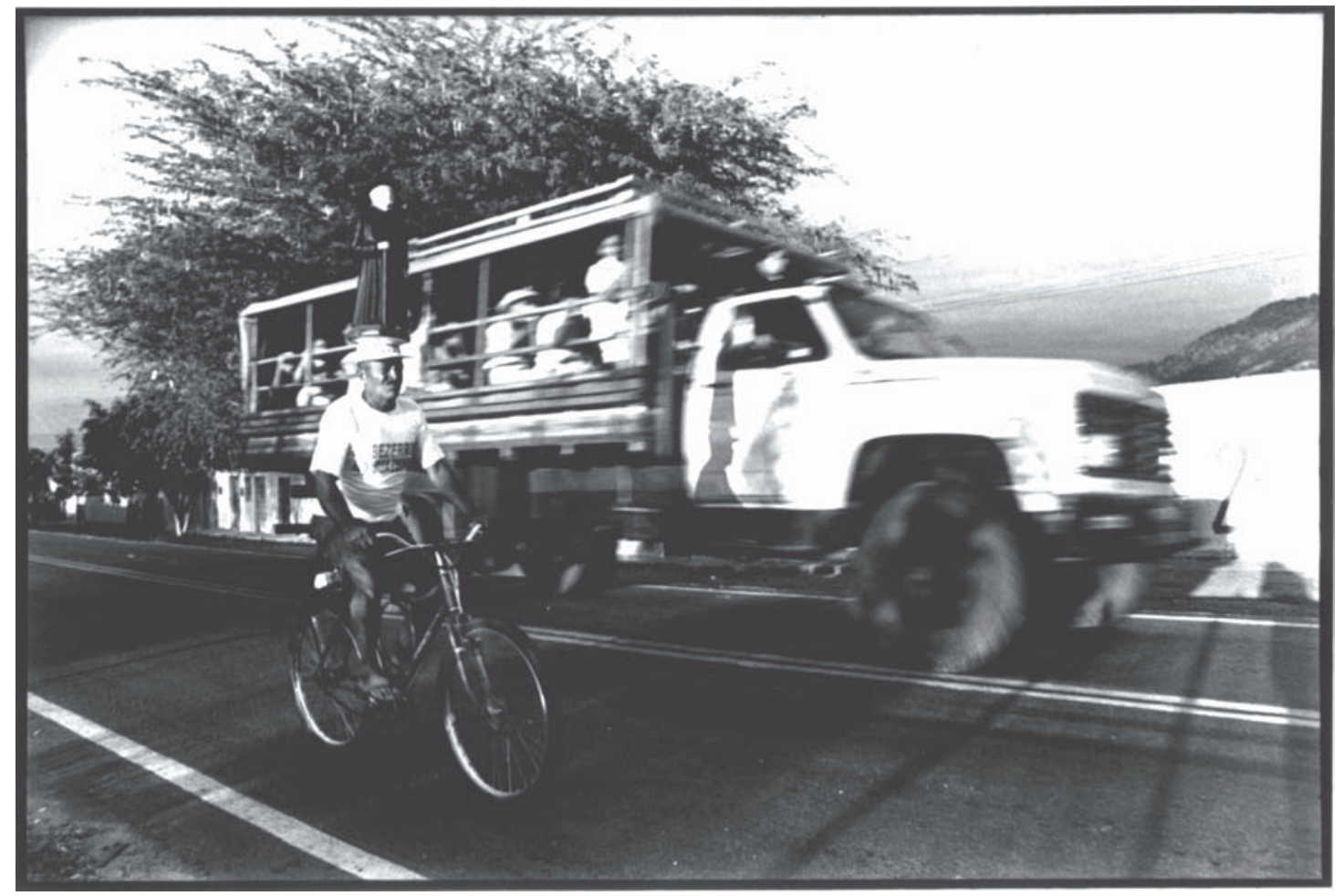

José Bassit - Juazeiro do Norte, Ceará, 2000

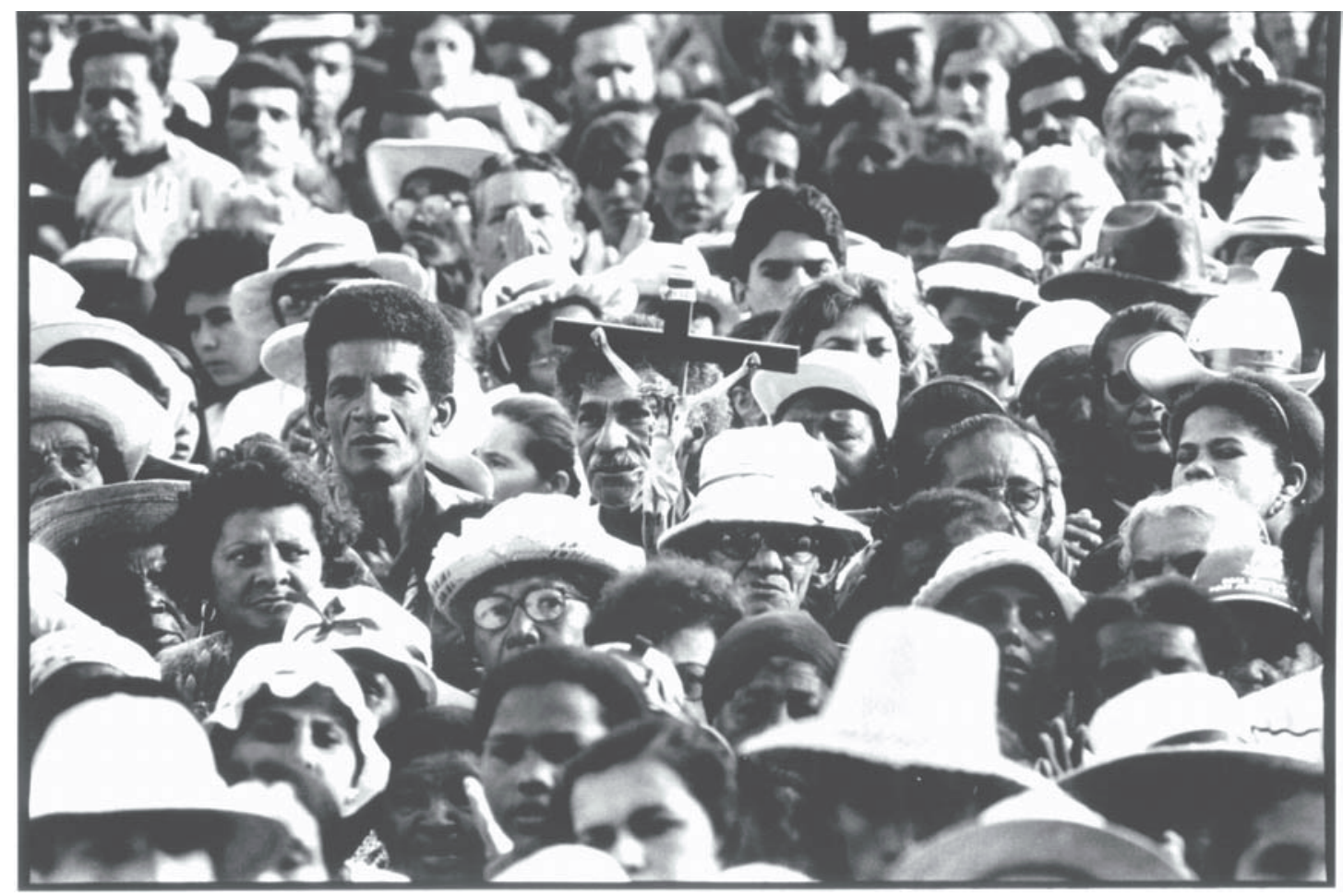

José Bassit - Festa do Santuário, Bom Jesus da Lapa, Bahia, 2000 


\section{Conclusão}

São dados consistentes os que nos fornecem os censos demográficos do IBGE. Para quem se interessa pela dinâmica do campo religioso, que segundo Bourdieu é, a um só tempo, campo de forças, campo de jogo e campo de batalha, as estatísticas que aqui apresentei e procurei analisar na medida do possível são, além de inteiramente consistentes com a teorização sociológica mais canônica, muito significativas. E mais significativas foram ficando à medida que, ao examinar um depois do outro os censos das últimas décadas, dispondo então os números referentes às religiões em seqüências de recorte variado, as tabelas me passaram a entregar, bem delineadas, as trajetórias declinantes que a teoria sociológica fazia-me supor estivessem ocorrendo. Passos sólidos, foi o que pude, na rota da destradicionalização cultural do País. Mergulhos líquidos, valha-me a verve metaforizante de Zygmunt Bauman ${ }^{12}$, nas águas inconstantes do pós-tradicional tardo-moderno, dora em diante vivido também em religião.

Notas

1 Ver Isaía, 2003, pp. 250 e ss.

2 Ver Della Cava, 1975, pp. 14-15.

3 Ver Montero, 1999, pp. 338 e ss.

4 Julgo eu.

5 Candido Procópio Ferreira de Camargo, Católicos, protestantes, espiritas. Petrópolis, Vozes, 1973, p. 24.

6 Idem.

7 Ver Camargo, 1973, p. 122.

8 Ver Mariano, 2001, p. 32.

9 Ver Negrão, 1996, p. 113.

10 Idem, pp. 131 e ss.

11 Ver a respeito o artigo de Reginaldo Prandi neste dossiê.

12 Ver Bauman, 2001.

Bibliografia

BAUMAN, Zygmunt. Modernidade líquida. Rio de Janeiro, Jorge Zahar, 2001.

CAMARGO, Candido Procopio Ferreira de (org.). Católicos, protestantes, espiritas. Petrópolis, Vozes, 1973.

DELLA CAVA, Ralph. "Igreja e Estado no Brasil do século XX: sete monografias recentes sobre o catolicismo brasileiro, 1919-64". Estudos Cebrapno 12, abr.-jun., 1975, pp. 5-52. 
ISAÍA, Artur Cesar. "A hierarquia católica brasileira e o passado português”. Em SZESZ, Christiane Marques et al. (orgs.). Portugal-Brasil no século XX: sociedade, cultura e ideologia. Bauru, Edusc, 2003, pp. 233-253.

LEVY, Maria Stella Ferreira. The Umbanda is for All of Us. University of Wisconsin, 1967.

MONTERO, Paula. "Religiões e dilemas da sociedade brasileira". Em MICELI, Sergio (org.). O que ler na ciência social brasileira (1970-1995). São Paulo, Sumaré/Anpocs, 1999 , pp. 327-367.

NEGRÃO, Lísias Nogueira. Entre a cruz e a encruzilhada. São Paulo, Edusp, 1996.

RESUMO - NO CAMPO das religiões em nosso País, estamos diante de mudanças sociais aceleradas. Elas são principalmente culturais, mas têm importante dimensão demográfica e é justamente para salientar a significação sociológica mais ampla dessa dimensão populacional inevitável, que o artigo elege o ponto de vista do declínio demográfico de três das nossas religiões tradicionais: o catolicismo, o luteranismo e a umbanda. São mutações socioculturais de monta essas que o censo demográfico de 2000 descreve com números checados e rechecados por pessoal técnico da maior competência, dotados, por isso, da vantagem comparativa de ser altamente confiáveis, diferindo nesse aspecto dos dados quantitativos que circulam normalmente na mídia, provenientes não raro de fontes religiosas de (des)informação.

ABSTRACT - SWIFT social changes are occurring in Brazil's religious milieu. Although these changes are mainly cultural, there is an important demographic dimension as well. It is precisely to highlight the greater sociological significance of this inescapable component that we chose the viewpoint of the demographic decline of three religions: Catholicism, Lutheranism and Umbanda. These are momentous sociocultural mutations, as described by 2000 demographic Census, founded on data that was checked and double checked by highly qualified technical personnel. Thus, the figures have the comparative advantage of being highly trustworthy, unlike the quantitative data normally conveyed by the media, not rarely originating from religious sources of (dis)information.

Antônio Flávio Pierucci é livre-docente do Departamento de Sociologia da Faculdade de Filosofia, Letras e Ciências Humanas da USP.

Texto recebido e aceito para publicação em 14 de agosto de 2004. 